\title{
Imaging diagnosis of classical and new pneumoconiosis: predominant reticular HRCT pattern
}

\author{
Akira Masanori* ${ }^{*}$
}

\begin{abstract}
Our understanding of the manifestations of pneumoconioses is evolving in recent years. Associations between novel exposures and diffuse interstitial lung disease have been newly recognized. In advanced asbestosis, two types of fibrosis are seen, probably related to dose of exposure, existence of pleural fibrosis, and the host factor status of the individual. In pneumoconiosis of predominant reticular type, nodular opacities are often seen in the early phase. The nodular pattern is centrilobular, although some in metal lung show perilymphatic distribution, mimicking sarcoidosis. High-resolution computed tomography enables a more comprehensive correlation between the pathologic findings and clinically relevant imaging findings. The clinician must understand the spectrum of characteristic imaging features related to both known dust exposures and to historically recent new dust exposures.
\end{abstract}

Keywords: Pneumoconiosis, Asbestosis, HRCT, Metal lung disease

\section{Key points}

- The radiological pattern of known pneumoconiosis is changing in recent years.

- In advanced asbestosis, two types of fibrosis are seen on HRCT, probably related to dose of exposure, existence of pleural fibrosis, and the host factor status of the individual.

- Similar and different pathologic and radiologic findings are seen in each metal lung disease.

- The clinician must understand the spectrum of typical HRCT features related to dust exposures.

\section{Introduction}

Pneumoconiosis is a classic disease, but exposures to asbestos and silica dust still affect workers. Asbestos and other harmful minerals have been used worldwide.

*Correspondence: akira.masanori.rp@mail.hosp.go.jp

Department of Radiology, NHO Kinki-Chuo Chest Medical Center, 1180

Nagasone-cho, Kita-ku, Sakai City, Osaka 591-8555, Japan
Asbestos has been banned in the industrialized countries. Even now, there are many people in the world who are associated with mining, production, and uses of asbestos and other harmful minerals in the workplace. Professions and products that have risk of exposure to each of the pneumoconiosis are listed in Table 1.

Classical pneumoconiosis is changing the typical pattern. The prevalence of severe and rapidly progressive pneumoconiosis is increasing [1]. The imaging features of metal-related lung disease, such as hard metal lung and aluminosis, have not been completely understood. Associations between novel exposures and diffuse interstitial lung disease or terminal airways disease have newly recognized $[2,3]$.

Correlation of high-resolution CT (HRCT) features with history of exposure is most important for the diagnosis of pneumoconiosis. HRCT features of predominant reticular type pneumoconiosis can mimic those of idiopathic interstitial pneumonias. In this article, we demonstrate pathology and HRCT findings of asbestosis, uncommon pneumoconioses, and newly recognized 
Table 1 Professions and products that have risk of exposure to each of the pneumoconiosis

\begin{tabular}{ll}
\hline Agent & Professions and products \\
\hline Asbestosis & $\begin{array}{r}\text { Hard rock mining, construction, road work, tunneling, sandblasting, foundry work, glass manufacture, asbestos-cement } \\
\text { products, asphalt floorings, floor tiles, asbestos textiles, asbestos paper products, friction materials } \\
\text { Talc pneumoconiosis }\end{array}$ \\
$\begin{array}{l}\text { Paints, cosmetic powders, soapstone, ceramics, asphalt, shoe polish, roofing felts, rubber, fertilizer, refractory filler, paper, } \\
\text { textiles }\end{array}$ \\
$\begin{array}{l}\text { Refining of bauxite, aluminum smelting, abrasives, aluminum arch welders, aluminum powder, building materials, glass } \\
\text { manufacture } \\
\text { Indium lung }\end{array}$ \\
$\begin{array}{l}\text { Hard metal production, grinding, diamond polishing } \\
\text { Transparent electrodes for liquid crystal displays, touchscreens and solar cells, semiconductors }\end{array}$
\end{tabular}

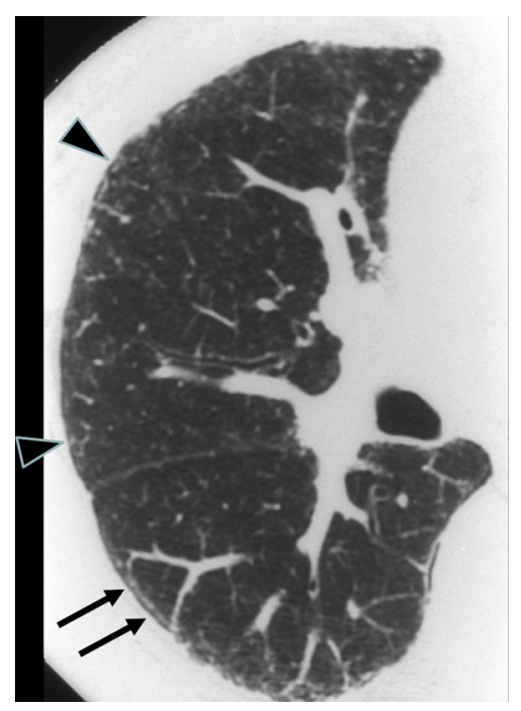

Fig. 1 Subpleural dots and subpleural lines in asbestosis. Some dots are located a few millimeters from the pleura (arrows). In asbestosis, subpleural line is much closer to the pleural surface and the distance of the subpleural lines from the inner chest wall is 2 to $3 \mathrm{~mm}$ (arrowheads). The subpleural lines look like connected subpleural dots arranged along the inner chest wall

pneumoconioses. Compared to chest radiography, HRCT offers improved correlations between histopathologic and clinically relevant imaging findings [4-7].

\section{Asbestosis}

In early asbestosis, the fibrotic process is limited to the walls of alveoli around the bronchioles. From this centrilobular position, fibrosis extends outward until it ultimately links adjacent bronchioles [8]. The fibrotic process affects the lower lobes of the lungs and may extent to the middle and upper lobes. In a study of the deposition and clearance of asbestos in rats using radioactive tracer techniques, autoradiographs of lung sections indicated that alveolar deposition was relatively uniform initially, that over a period of several months the uniform distribution changed to one in which fibers accumulated in foci that are mainly subpleural, and that these foci acted as centers for the development of nodular fibrosis [9].

In the early stage of asbestosis, the HRCT findings include subpleural dot-like structures, subpleural lines, intralobular interstitial thickening, interlobular septal thickening, ground-glass opacities, and parenchymal bands [4-6]. CT-pathologic correlation shows that the subpleural dot-like structures correspond to peribronchiolar fibrosis with subsequent involvement of the alveolar ducts and that the subpleural lines correspond to peribronchiolar fibrosis combined with flattening and collapse of the alveoli. Subpleural dot-like structures arranged along the inner chest wall create subpleural lines (Fig. 1) [7].

In advanced asbestosis, there are two patterns of parenchymal abnormalities, i.e., honeycombing and atelectatic induration fibrosis (Fig. 2a, b) [10]. The frequency of honeycombing on HRCT scans is $17-32 \%[4,11,12]$. Atelectatic induration fibrosis is characterized by a combination of collapse and collagenous fibrosis filling the alveolar lumens $[8,10]$. The atelectatic induration type evolves much more rapidly and is related to high exposures. Atelectatic induration fibrosis is now rarely encountered in industrialized nations; however, such disease is likely to develop if asbestos dust control is neglected [8]. In a study, atelectatic induration fibrosis type showed $920,000 \pm 1,360,000$ asbestos fibers/g of dry lung, whereas honeycomb type showed 200,000 $\pm 490,000$ asbestos fibers $(p<0.01)$ [13]. The characteristic HRCT finding is honeycombing, mimicking usual interstitial pneumonia (UIP). The HRCT findings of atelectatic induration fibrosis type are characterized by consolidation with loss of volume and traction bronchiectasis in the consolidated areas. Honeycombing is rare on the images. Pleural plaques, subpleural dots, and subpleural lines are present in both types. Diffuse pleural thickening is more frequent in the atelectatic induration fibrosis type than in the honeycomb type [13]. In patients with advanced disease, subpleural dot-like structures and subpleural lines 


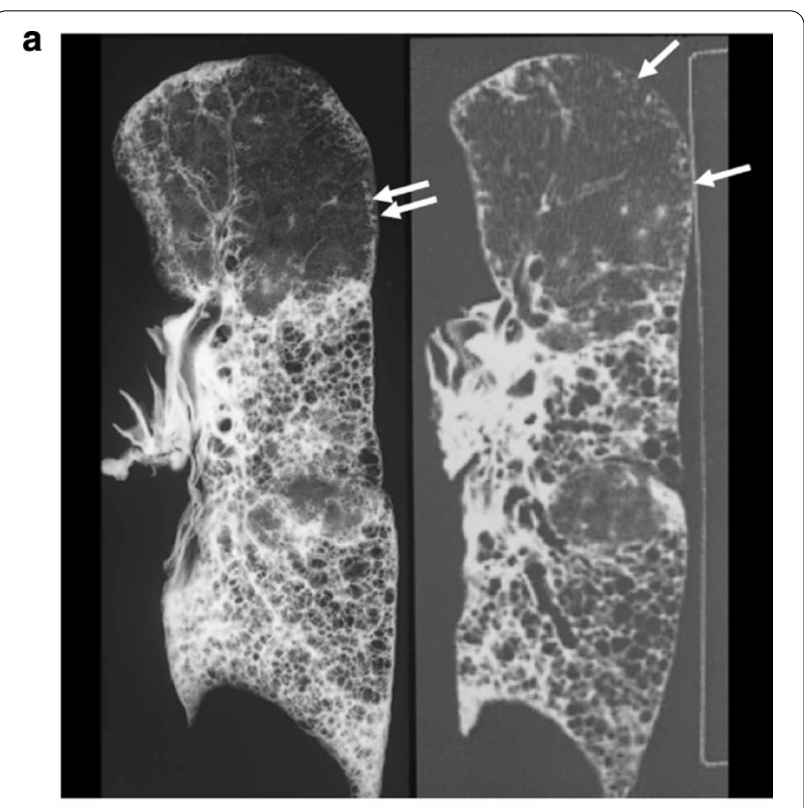

b

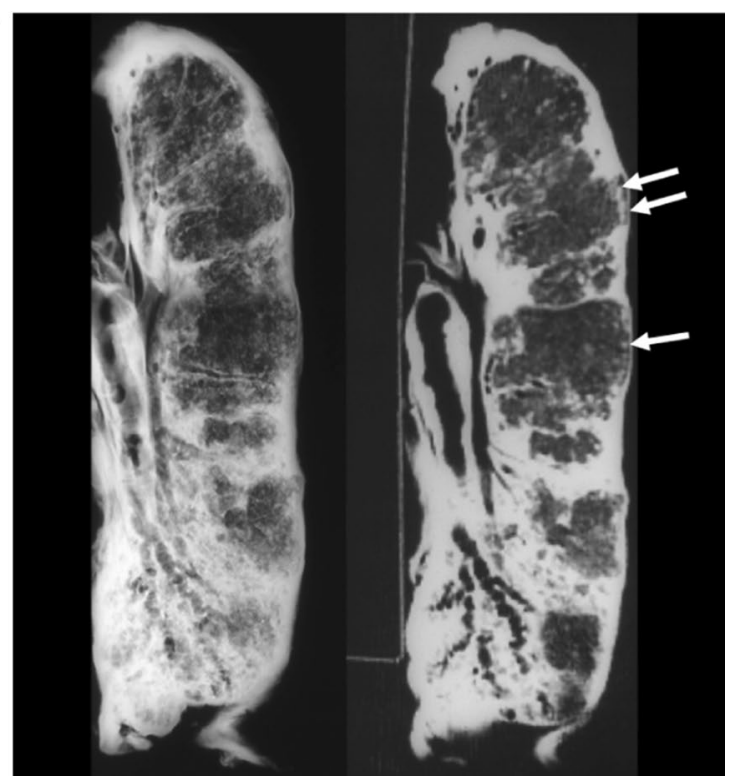

Fig. 2 Two types of advanced asbestosis. a A honeycomb type of asbestosis. Postmortem low-kilovoltage radiograph and $\mathrm{HRCT}$ scan of the inflated and fixed left lung shows honeycombing in the lower two-thirds of the lung. In the subpleural zones of upper lung, dot-like lesions are seen (arrows). $\mathbf{b}$ An atelectatic fibrosis type of asbestosis. Postmortem low-kilovoltage radiograph and HRCT scan of the inflated and fixed left lung shows diffuse pleural thickening and consolidated area extending along the bronchovascular sheath. Traction bronchiectasis is seen in the consolidated area. Honeycombing is not seen radiologically. In the subpleural zones of upper lung, subpleural dots and subpleural lines are also seen (arrows)

are found in less severely involved regions of the pulmonary parenchyma [11].
In a cohort referred for diagnosis of an asbestos-related malignancy in the context of litigation, sixty-five cases with both adequate tissue sampling for histopathologic evaluation of asbestos and radiographic assessment of pulmonary fibrosis reported by B-reader who is a physician certified by the National Institute for Occupational Safety and Health (NIOSH) as demonstrating proficiency in classifying radiographs of the pneumoconioses were examined [14]. Of these, 24 cases were diagnosed as positive for asbestosis based on exposure and the presence ILO standard of profusion $1 / 0$ or greater. The six cases of those 24 cases showed histologically proven asbestosis. The remaining 18 cases with $B$ readings $\geqq 1 / 0$ showed interstitial fibrosis consistent with smoking-associated pulmonary fibrosis [14]. Another two cases showed histopathologic evidence of asbestosis but an ILO profusion of $<1 / 0$. It may be possible that persons having many diseases other than asbestosis are included under asbestosexposed persons with B readings $\geqq 1 / 0$.

The principal differential diagnosis of asbestosis is from idiopathic pulmonary fibrosis (IPF). Copley et al. [15] concluded that the HRCT pattern of asbestosis closely resembled that of UIP and differed markedly from that of nonspecific interstitial pneumonia (NSIP). They found that patients with asbestosis had coarser fibrosis than those with IPF but not when the analysis was confined to biopsy-proved UIP.

Cysts in asbestosis rarely exceed about $3 \mathrm{~mm}$ in diameter when present, but macrocystic honeycombing can be seen in asbestosis. Histopathologically, some cases of asbestosis resemble UIP, while others resemble fibrotic NSIP [8]. It is also said that the changes resemble those of NSIP, or more rarely UIP pathologically [16]. The fibroblastic foci that characterize the UIP pattern of fibrosing alveolitis are seldom observed in asbestosis [8].

The clinical progression is slow or has stabilized over time in asbestosis, as opposed to IPF. However, some of the past cases evolved much more rapidly, presumably related to high exposures.

In the study of pathologic and HRCT evaluation for 33 asbestos workers [17], 15 cases were pathologically diagnosed as asbestosis and 18 cases as various lung fibroses other than asbestosis. They concluded that on HRCT, subpleural lines were the only clue for the diagnosis of asbestosis. Mixed dust fibrosis and chronic interstitial pneumonia of unclassifiable histopathology, which are airway-centered, were included in the study. They may have centrilobular nodules, however, seldom show subpleural dot-like structures along with the pleural surface which create subpleural lines (Fig. 2). Moreover, there is a significant difference between IPF and asbestosis in pleural changes. 

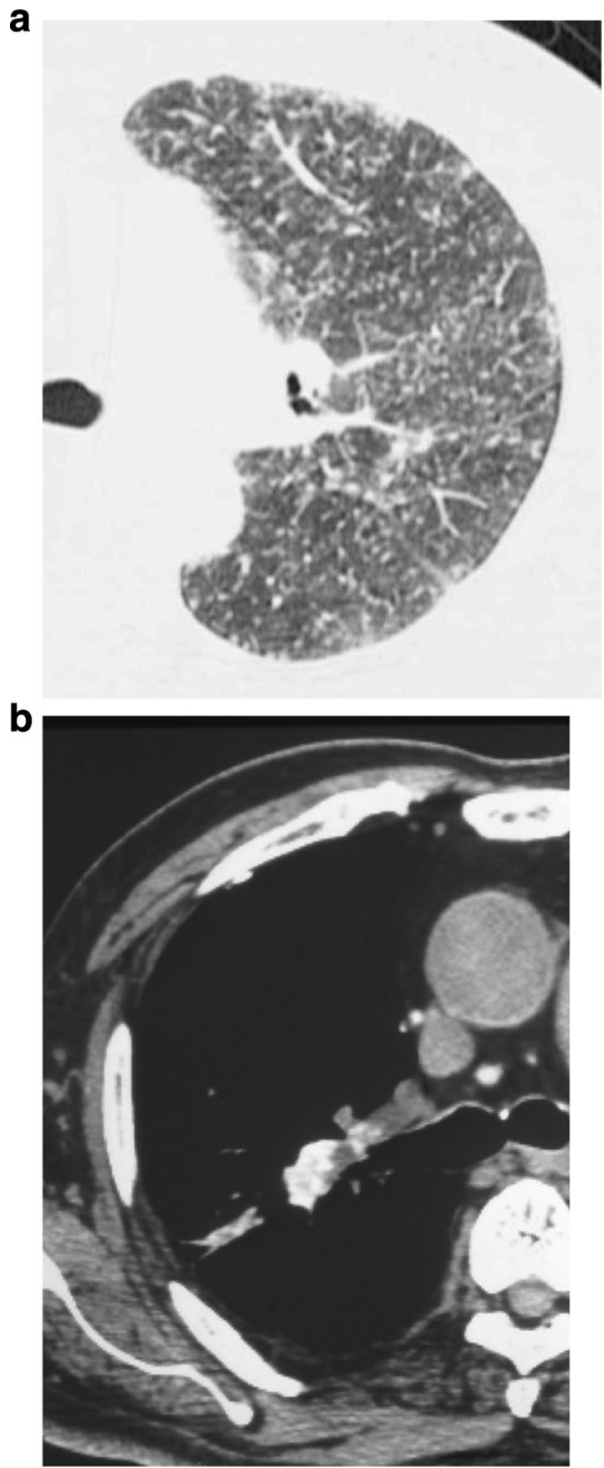

Fig. 3. 61-year-old man with inhalational talc pneumoconiosis employed in talc industry for 20 years. a HRCT scan shows diffusely distributed small nodules. They are separated from the pulmonary vein or the pleura at a distance of about $2-3 \mathrm{~mm}$ and are separated regularly from each other at a distance of about $2-3 \mathrm{~mm}$. b CT scan at mediastinal setting of 61-year-old man with inhalational talc pneumoconiosis shows large opacity and lymph nodes containing high-attenuation material

\section{Talc pneumoconiosis}

High-resolution CT findings in talcosis from inhaled talc consist of diffuse small centrilobular nodules (Fig. 3a), ground-glass opacities, and heterogeneous conglomerate masses with high-attenuation areas consistent with talc deposition. The parenchymal abnormalities are diffuse but most severe in the upper and middle lung zones with relative sparing of the lung bases [18-21].
Conglomerated masses in silicosis usually involve the upper-lung zones, while in talcosis they are distributed throughout all lung zones [20, 21]. In talcosis observed in soapstone artisans, interlobular septal thickening was found in all patients, in addition to small centrilobular nodules (75\%) and ground-glass opacity (67\%) [22]. Slight lymph node enlargement with increased attenuation is visible in some cases of talcosis (Fig. 3b). Increased CT attenuation of lymph nodes and large opacities is caused by large numbers of talc particles [21].

CT findings in talcosis from injected talc include diffuse small nodules, perihilar conglomerated masses with areas of high attenuation, ground-glass opacities, and, particularly in patients with talcosis secondary to methylphenidate abuse, panacinar emphysema [19, 23, 24]. IV talcosis is usually hematogenous in distribution. The small nodules have a predominantly perivascular

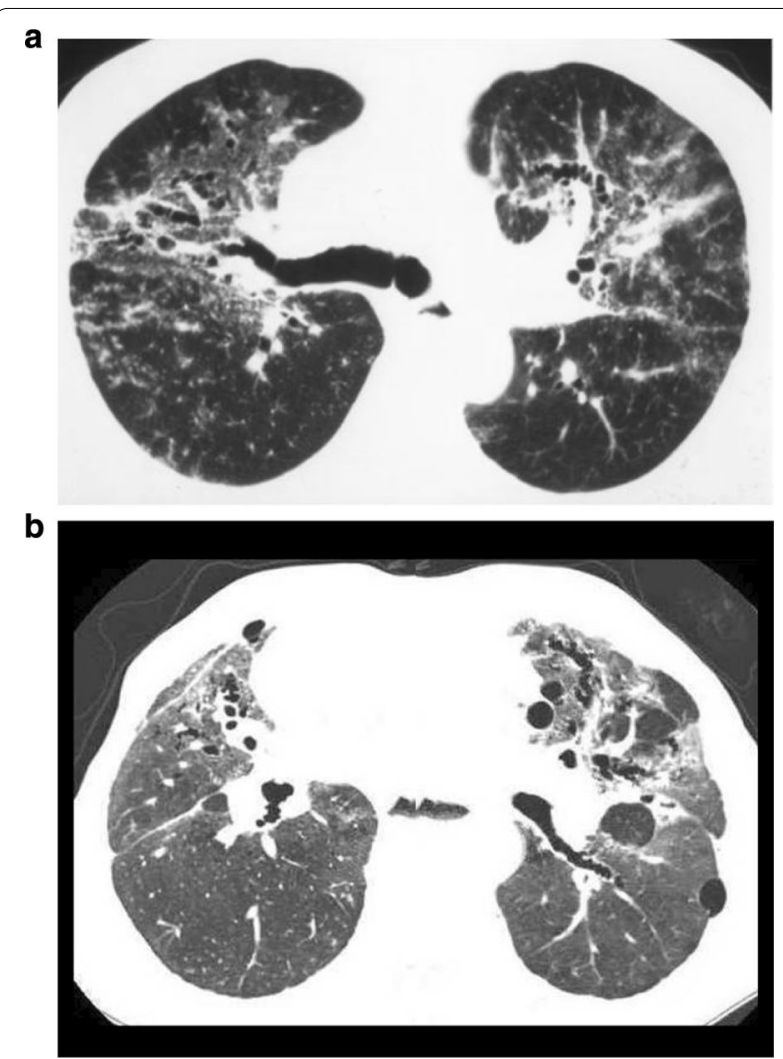

Fig. 4 HRCT scans of pulmonary aluminosis. a 58-year-old man with pulmonary aluminosis. HRCT scan of pulmonary aluminosis mimicking sarcoidosis. Ground-glass opacities, small nodular opacities, and traction bronchiectasis are seen predominantly around the bronchovascular bundles. Nodules are located in both centrilobular and paralobular regions. b 52-year-old man with pulmonary aluminosis. HRCT shows traction bronchiectasis and ground-glass opacity predominantly in the upper lungs. Multiple bullae and centrilobular nodules are also seen 
Fig. 5 HRCT scans of heard metal pneumoconiosis. a 62-year-old man with hard metal pneumoconiosis. Upper-lung predominant fibrosis in hard metal pneumoconiosis. HRCT scan shows prominent interstitial thickening, irregular peribronchovascular thickening, and traction bronchiectasis in upper lung zones. b 32-year-old man with hard metal pneumoconiosis. Early stage of hard metal pneumoconiosis. HRCT scan shows ground-glass opacities and centrilobular nodules predominantly in the peripheral portions. $\mathbf{c}$ 53-year-old man with hard metal pneumoconiosis. HRCT scan shows patchy and irregular ground-glass opacity and traction bronchiectasis diffusely distributed in the lung. Bullae are seen in the subpleural region.

distribution. A case of pulmonary intravascular talcosis mimicking military tuberculosis has been reported [25].

\section{Metal-related lung diseases}

Inhalation of metals and their fumes can induce a wide range of lung pathology, including granulomatous disease, giant cell interstitial pneumonitis (GIP), chemical pneumonitis, interstitial fibrosis, airways disorders, and cancer. Metals such as aluminum, cobalt, copper, and indium induce pulmonary fibrosis. Metal-induced pulmonary fibrosis has some similarities.

\section{Aluminum pneumoconiosis}

Aluminum lung is characterized by diffuse interstitial fibrosis mainly located in the upper and middle lobes of the lung. In the early stages of aluminosis, the HRCT findings are characterized by small rounded and illdefined centrilobular opacities mainly in the upper lobes $[26,27]$. Alveolar septal fibrosis or centrilobular nodules under the resolution of HRCT scans create ground-glass opacity. In addition to centrilobular nodules, the nodular pattern in aluminosis includes nodules in lymphatic distribution mimicking sarcoidosis, probably reflecting a granulomatous lung reaction (Fig. 4a, b).

In advanced stages, it is characterized by subpleural bullous emphysema with an increased risk of spontaneous pneumothorax [28]. The HRCT appearances of aluminum pneumoconiosis may be variable and include nodular, reticular, and upper lung fibrosis pattern (Fig. 4a, b) [28]. Conglomerated masses mimicking silicosis are thought to be affected by exposure to silica other than aluminum dust. Interstitial lung disease in corundum (aluminum oxide) abrasive workers can be accelerating silicosis or mixed dust fibrosis.

Increased attenuation of mediastinal lymph nodes with histologically proven aluminum storage can be seen on CT scans [29].
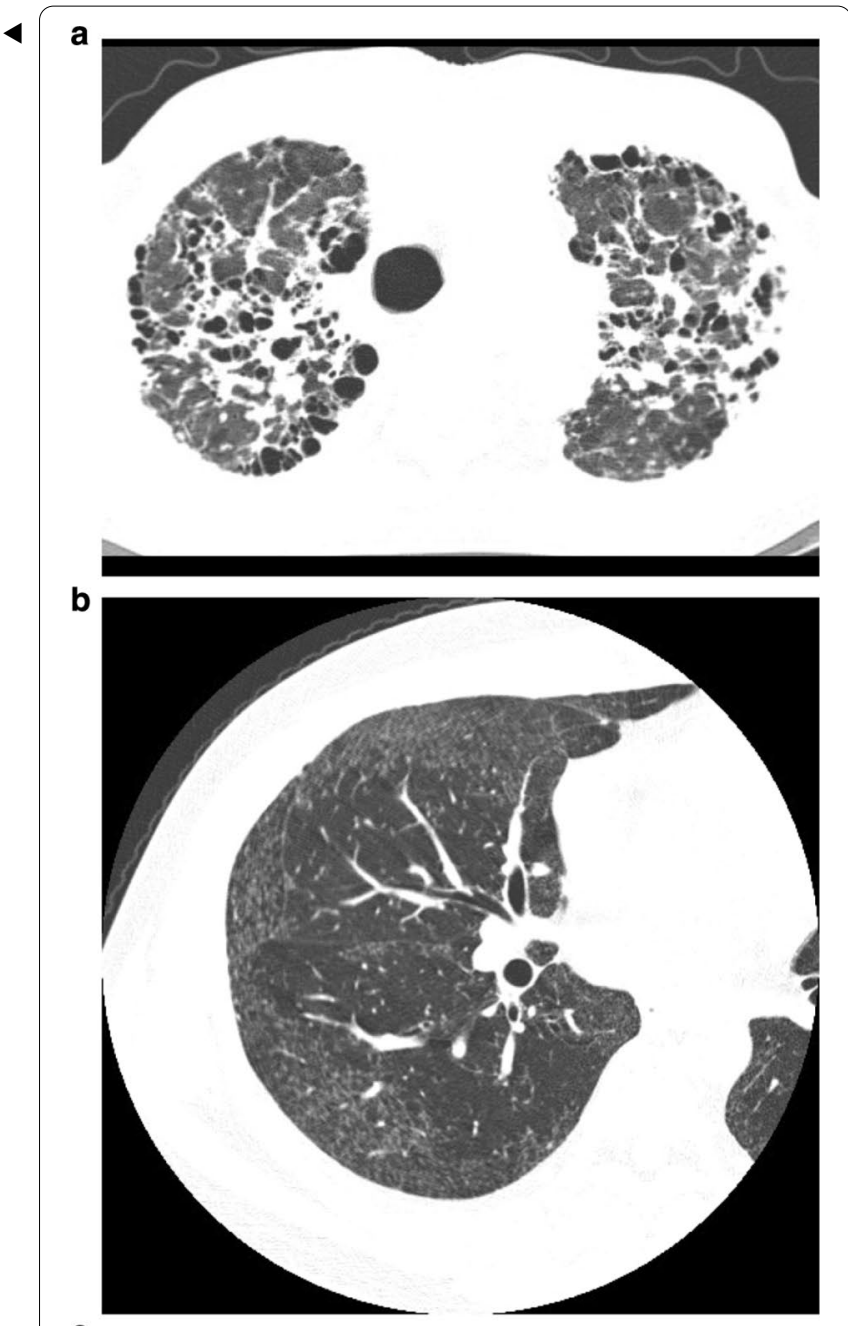

C

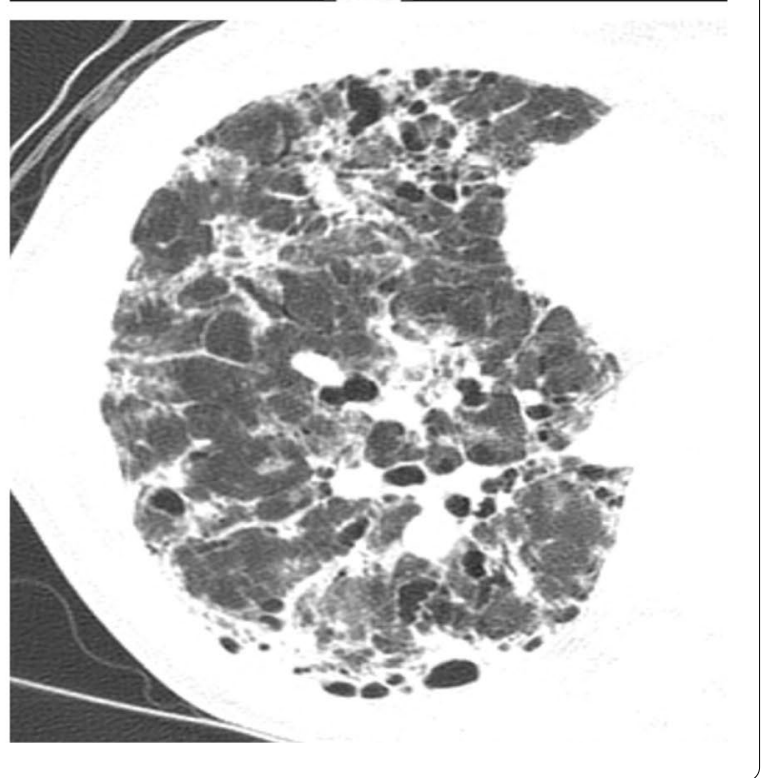




\section{Hard metal pneumoconiosis}

Exposure to hard metal causes asthmatic reaction, hypersensitivity pneumonitis, and pulmonary fibrosis [30]. Patients typically present with hard metal interstitial lung disease after 10-12 years of exposure, but the disease can occur in as little as 2 years [31]. GIP is the classic pathology of cobalt related interstitial lung disease. GIP is characterized by a chronic interstitial pneumonia with fibrosis that is typically bronchiolocentric [32].

The HRCT appearance of hard metal interstitial lung disease may be variable and may mimic sarcoidosis, NSIP, UIP, and fibrotic hypersensitivity pneumonitis [28, 33-37]. As for the predominant distribution of parenchymal abnormalities, both upper predominant (Fig. 5a) and lower predominant distribution are reported to the same degree. The major HRCT findings are ground-glass opacities. The ground-glass opacities show diffuse, patchy, or lobular distribution. Reticular opacities and small nodular opacities are also seen. The small nodules are distributed mainly in centrilobular location [28, 35-37]. Some patients show perilymphatic distribution, mimicking sarcoidosis $[33,36]$. In some cases with hard metal pneumoconiosis, the predominant HRCT finding is centrilobular nodules. The centrilobular nodules on HRCT correspond to the histologic finding of bronchiolocentric fibrosis [28]. Ground-glass centrilobular nodules and air trapping are the predominant findings in cobalt-related ILD with a HP pattern [38].

In the early stages of hard metal pneumoconiosis, the HRCT scan shows ground-glass opacities and centrilobular nodules (Fig. 5b) [39]. Traction bronchiectasis and architectural distortion are seen in advanced cases. Clustered cystic lesions are also seen and consist of traction bronchiectasis and bronchiolectasis, and bullae (Fig. 5c). Consolidation is a rare finding, seen in a fatal case [28]. Peripheral cystic spaces are reported in some cases [28, $33,40]$. Lymph node enlargement and spontaneous pneumothorax have been reported [30].

Progression of fibrosis in hard metal lung disease is very different from case to case (Fig. 6). The progression is slow in some cases, and others rapidly deteriorate [28, $31,41]$. Ground-glass opacities are reported to improve following cessation of exposure to hard metal and treatment [35]. Patients with fibrosis are less likely to experience disease remission.

\section{Indium lung disease}

Workplace exposure to indium compounds including indium oxide and indium-tin oxide causes several lung diseases; pulmonary fibrosis, emphysema and pulmonary alveolar proteinosis (PAP). Ten clinical cases of lung disease in indium workers from three countries (Japan, United States, and China) had been reported [42,

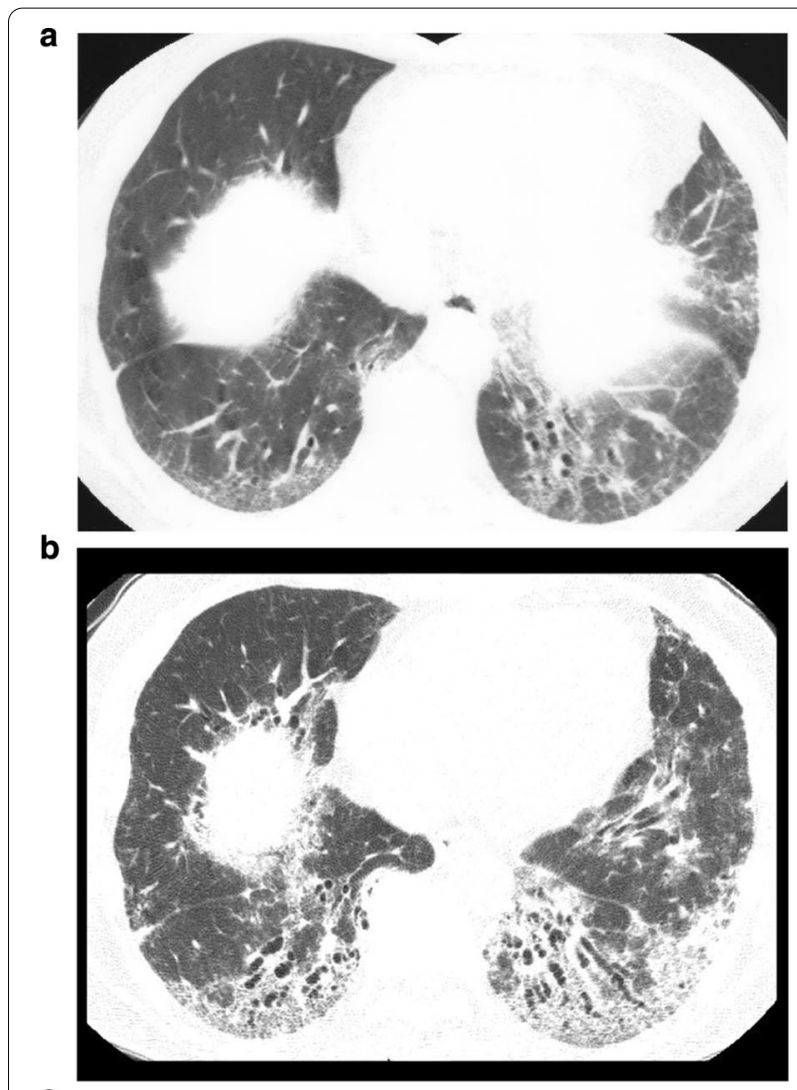

c

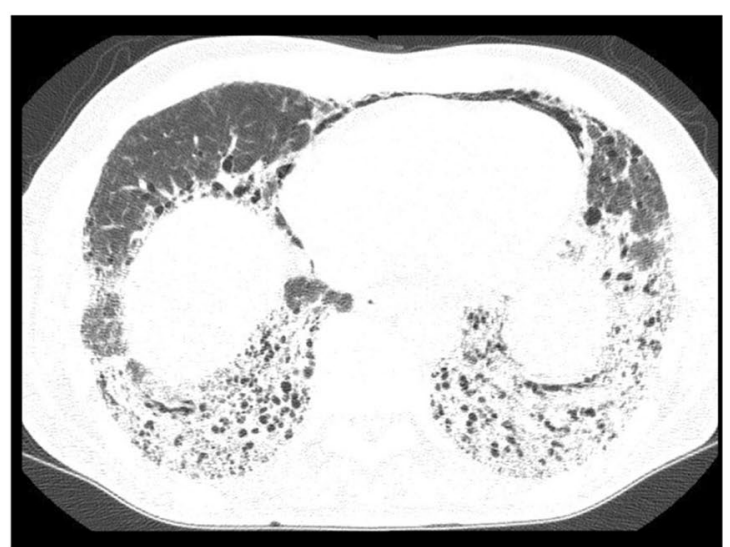

Fig. 6. 59-year-old man with hard metal pneumoconiosis. Initial HRCT scan (a) shows scattered areas of ground-glass attenuation associated with fine reticulation and mild traction bronchiectasis. HRCT obtained 3 years later $(\mathbf{b})$ reveals increase in parenchymal abnormalities in extent, prominent reticulation, and progression of traction bronchiectasis. HRCT obtained 5 years later (c) shows dense increased parenchymal opacities with traction bronchiectasis

43]. Among the reported cases, those with shorter diagnostic latency had findings more consistent with PAP, while cases with longer diagnostic latency had findings more consistent with interstitial lung disease. Two patients initially diagnosed with PAP had radiographic 


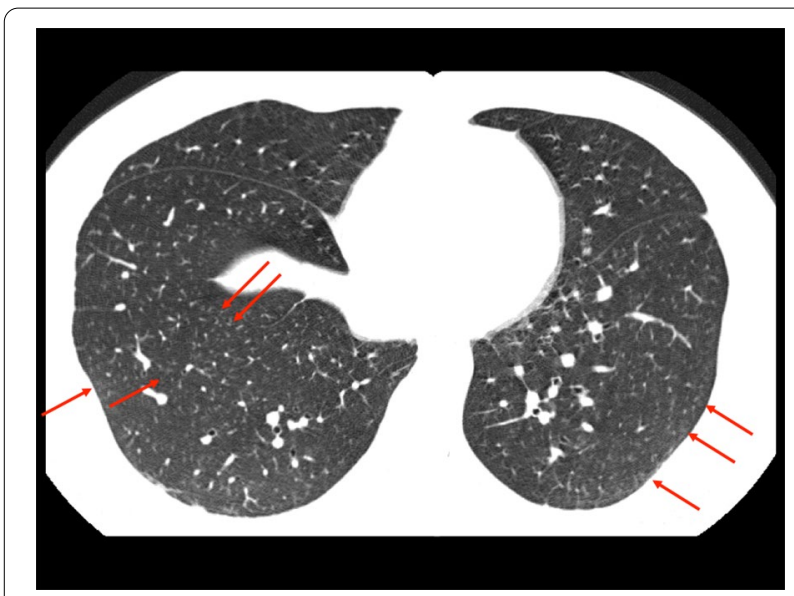

Fig. 7 HRCT scan of a 34-year-old man with indium lung. Tiny centrilobular nodules (arrows) are scattered in both lungs

progression to fibrosis over several years [43]. Amata et al. reported that radiographic interstitial changes can be reduced in indium workers by cessation of exposure to indium, whereas emphysematous lesions can progress among those with a history of heavy exposure [44]. An advanced case of indium lung disease with severely progressive emphysema has been reported [45].

In cases with interstitial lung disease, the major HRCT findings are ground-glass opacities and/or centrilobular opacities (Fig. 7) [43]. The parenchymal abnormalities show diffuse, upper or mid-lung predominance, and sometimes lower-lung predominance. Interstitial opacities with volume reduction and traction bronchiectasis in the upper lungs are reported [42]. Paraseptal emphysema, small cysts at both apices and subpleural honeycomb can be seen [42].

\section{Nylon flock worker's lung}

In nylon flock worker's lung, histopathologic evaluation commonly shows a NSIP pattern with lymphocytic bronchiolitis with peribronchovascular interstitial lymphoid infiltrates. Other secondary histological features that were variably present include diffuse alveolar damage (DAD), bronchiolitis obliterans with organizing pneumonia (BOOP), and desquamative interstitial pneumonia (DIP) [46-48]. HRCT appearances reflect these histopathologic findings.

The most common imaging findings in flock workers' lung are ground-glass opacities and micronodules predominantly distributed in the centrilobular region. The parenchymal abnormalities are diffuse, patchy, or predominantly show a basal and peripheral pattern. Reticular opacities, traction bronchiectasis, septal thickening, and consolidation are also seen [46-49]. In some cases, HRCT shows extensive basal-predominant ground-glass opacity similar to that seen in NSIP or DIP. In advanced stages, HRCT shows subpleural-predominant reticular abnormalities associated with honeycombing and traction bronchiectasis similar to that of UIP [49].

Flock workers' lung shows profuse micronodules and more extensive ground-glass opacity compared to IPF. These HRCT features are included under non-UIP patterns that are considered to be inconsistent with IPF in the 2011 American Thoracic Society/European Respiratory Society/Japanese Respiratory Society/Latin American Thoracic Association guidelines [50].

\section{Newly recognized pneumoconioses}

In addition to indium lung disease and flock workers' lung, recent studies have linked new causative occupational and environmental agents with both airways

Table 2 Newly recognized pneumoconioses

\begin{tabular}{|c|c|c|c|}
\hline Agent & Causative agent & Characteristic histopathology & CT findings \\
\hline Indium lung & Indium-tin oxide & Interstitial fibrosis, PAP, emphysema & $\begin{array}{l}\text { Ground-glass opacities, centrilobular nodules, } \\
\text { traction bronchiectasis, crazy-paving appear- } \\
\text { ance, LAA }\end{array}$ \\
\hline Nylon flock worker's lung & Nylon fibers & NSIP with lymphocytic bronchiolitis, DIP & $\begin{array}{l}\text { Diffuse micronodular opacities, patchy consolida- } \\
\text { tion, honeycombing }\end{array}$ \\
\hline $\begin{array}{l}\text { Flavor worker's lung (Pop- } \\
\text { corn worker's lung) }\end{array}$ & Diacetyl & $\mathrm{BO}$ & Mosaic attenuation (air trapping) \\
\hline World-trade center lung & $\begin{array}{l}\text { Complex amalgam, } \\
\text { fiberglass, fly ash, silica, } \\
\text { asbestos, etc }\end{array}$ & $\begin{array}{l}\text { Asthmatic bronchiolitis, BO, AEP, sarcoid- } \\
\text { like granulomatosis }\end{array}$ & $\begin{array}{l}\text { Mosaic attenuation (air trapping), peripheral } \\
\text { consolidation, diffuse micronodules }\end{array}$ \\
\hline Nanoparticles & Carbon nanotubes, etc & Interstitial fibrosis & $\begin{array}{l}\text { Patchy ground-glass opacities, centrilobular nod- } \\
\text { ules, traction bronchiectasis }\end{array}$ \\
\hline Ardystil syndrome & Acramin-FWN & $\mathrm{OP}$ & Peripheral predominant patchy consolidation \\
\hline
\end{tabular}

PAP, pulmonary alveolar proteinosis; NSIP, nonspecific interstitial pneumonia; DIP, desquamative interstitial pneumonia; BO, bronchiolitis obliterans; AEP, acute eosinophilic pneumonia; OP, organizing pneumonia 
disease and parenchymal lung disease [2]. Representative examples are shown in Table 2 . The last four entities are not discussed in the text of the manuscript. Further studies on each entity are needed.

\section{Conclusion}

Asbestosis has two types of fibrosis, probably related to dose of exposure, existence of pleural fibrosis, and the host factor status of the individual. Metal-related lung diseases have similarities and differences irrespective of kinds of metal. Some of the radiologic and pathologic findings of pneumoconiosis resemble those of idiopathic interstitial pneumonias. Dust exposure can cause pathologic and radiologic changes indistinguishable from IPF. It is postulated that many types of dust exposures can increase risk of developing IPF [51]. HRCT reflects pathologic changes of pneumoconiosis. HRCT would enable a more comprehensive correlation between the pathologic findings and the clinically relevant imaging findings. Further study of HRCT of pneumoconiosis is warranted.

\begin{abstract}
Abbreviations
BOOP: Bronchiolitis obliterans organizing pneumonia; CT: Computed tomography; DAD: Diffuse alveolar damage; DIP: Desquamative interstitial pneumonia; GIP: Giant cell interstitial pneumonia; HP: Hypersensitivity pneumonitis; HRCT: High-resolution computed tomography; ILO: International Labour Organization; IPF: Idiopathic pulmonary fibrosis; NSIP: Non-specific interstitial pneumonia; PAP: Pulmonary alveolar proteinosis; UIP: Usual interstitial pneumonia.
\end{abstract}

\section{Acknowledgements}

I thank Drs. Narufumi Suganuma (Kochi University), Mika Nishimori (Kochi University), ans Nantaka Kiranantawat (Songklanagarind Hospital) for their assistance.

\section{Authors' contributions}

MA has contributed conception and design of the study, acquisition of data, analysis and interpretation of data, and drafting the manuscript. The author read and approved the final manuscript.

\section{Funding}

Partially supported by a grant to Grants-in-aid for Scientific Research [20H03931], Japan.

\section{Availability of data and materials}

The data are published in the article.

\section{Ethics approval and consent to participate}

Our Institutional Review Board approved that informed consent was unnecessary, because this study was retrospective and patient's name was blinded.

\section{Consent to publish}

Not applicable.

\section{Competing interests}

The author declares that he/she have no competing interests.

Received: 9 October 2020 Accepted: 11 January 2021

Published online: 10 March 2021

\section{References}

1. Cohen RA, Petsonk EL, Rose C et al (2016) Lung pathology in U.S. coal workers with rapidly progressive pneumoconiosis implicates silica and silicates. Am J Respir Crit Care Med 193:673-680

2. Sauler M, Gulati M (2012) Newly recognized occupational and environmental causes of chronic terminal airways and parenchymal lung disease. Clin Chest Med 33(4):667-680

3. Goldyn SR, Condos R, Rom WN (2008) The burden of exposure-related diffuse lung disease. Semin Respir Crit Care Med 29(6):591-602

4. Aberle DR, Gamsu G, Ray CS, Feuerstein IM (1988) Asbestos-related pleural and parenchymal fibrosis: detection with high-resolution CT. Radiology 166:729-734

5. Akira M, Yokoyama K, Yamamoto S et al (1991) Early asbestosis: evaluation with thin-section CT. Radiology 178:409-416

6. Gamsu G, Salmon CJ, Warnock ML, Blanc PD (1995) CT quantification of interstitial fibrosis in patients with asbestosis: a comparison of two methods. AJR Am J Roentgenol 164(1):63-68

7. Akira M, Yamamoto S, Yokoyama K et al (1990) Asbestosis: high-resolution CT-pathologic correlation. Radiology 176:389-394

8. Roggli VL, Gibbs AR, Attanoos R et al (2010) Pathology of asbestosis-an update of the diagnostic criteria: report of the Asbestos Committee of the College of American Pathologists and Pulmonary Pathology Society. Arch Pathol Lab Med 134:462-480

9. Morgan A, Evans JC, Holmes A (1975) Deposition and clearance of inhaled fibrous minerals in the rat: studies using radioactive tracer techniques. Inhaled Part 4(Pt 1):259-274

10. Yamamoto S (1997) Histopathological features of pulmonary asbestosis with particular emphasis on the comparison with those of usual interstitial pneumonia. Osaka City Med J 43(2):225-242

11. Akira M, Morinaga K (2016) The comparison of high-resolution computed tomography findings in asbestosis and idiopathic pulmonary fibrosis. Am J Ind Med 59(4):301-306

12. Al-Jarad N, Strickland B, Pearson MC, Rubens MB, Rudd RM (1992) High resolution computed tomographic assessment of asbestosis and cryptogenic fibrosing alveolitis: a comparative study. Thorax 47:645-650

13. Kawabata Y, Yamamoto S, Kishimoto T, Kobashi Y (2008) Macroscopic subtypes of asbestosis in relation to the amount of asbestos in 63 Japanese autopsy cases. Nihon Kokyuki Gakkai Zasshi 46:77-84 (in Japanese)

14. Bledsoe JR, Christiani DC, Kradin RL (2015) Smoking-associated fibrosis and pulmonary asbestosis. Int J Chron Obstruct Pulmon Dis 10:31-37

15. Copley SJ, Wells AU, Rubens MB et al (2003) Asbestosis and idiopathic pulmonary fibrosis: comparison of thin-section CT features. Radiology 229:731-736

16. Corrin B, Nicholson AG (2011) Asbestosis. In: Corrin B, Nicholson AG (eds) Pathology of the lung, 3rd edn. Churchill Livingstone, Edinburgh, pp 342-350

17. Arakawa H, Kishimoto T, Ashizawa Ket al (2016) Asbestosis and other pulmonary fibrosis in asbestos-exposed workers: high-resolution CT features with pathological correlations. Eur Radiol 26:1485-1492

18. Marchiori E, Lourenço S, Gasparetto TD, Zanetti G, Mano CM, Nobre LF (2010) Pulmonary talcosis: imaging findings. Lung 188:165-171

19. Padley SP, Adler BD, Staples CA, Müller NL (1993) Pulmonary talcosis: CT findings in three cases. Radiology 186:125-127

20. Marchiori E, Souza AS Jr, Muller NL (2004) Inhalational pulmonary talcosis: high-resolution CT findings in 3 patients. J Thorac Imaging 19(1):41-44

21. Akira M, Kozuka T, Yamamoto S, Sakatani M, Morinaga K (2007) Inhalational talc pneumoconiosis: radiographic and CT findings in 14 patients. AJR Am J Roentgenol 188:326-333

22. Pereira Faria P, de Souza Veiga A, Coutinho Teixeira L et al (2014) Talcosis in soapstone artisans: high-resolution CT findings in 12 patients. Clin Radiol 69(3):e136-e139

23. Ward S, Heyneman LE, Reittner P, Kazerooni EA, Godwin JD, Müller NL (2000) Talcosis associated with IV abuse of oral medications: CT findings. AJR Am J Roentgenol 174:789-793

24. Stern EJ, Frank MS, Schmutz JF, Glenny RW, Schmidt RA, Godwin JD (1994) Panlobular pulmonary emphysema caused by IV injection of methylphenidate (Ritalin): findings on chest radiographs and CT scans. AJR Am J Roentgenol 162:555-560

25. Altraja A, Jurgenson K, Roosipuu R, Laisaar T (2014) Pulmonary intravascular talcosis mimicking military tuberculosis in an intravenous drug addict. BMJ Case Rep. https://doi.org/10.1136/bcr-2014-203908 
26. Kraus T, Schaller KH, Angerer J, Letzel S (2000) Aluminium dust-induced lung disease in the pyro-powder-producing industry: detection by high-resolution computed tomography. Int Arch Occup Environ Health 73:61-64

27. Kraus T, Schaller KH, Angerer J, Hilgers RD, Letzel S (2006) Aluminosis detection of an almost forgotten disease with HRCT. J Occup Med Toxicol 1(4):1-9

28. Akira M (1995) Uncommon pneumoconioses: CT and pathologic findings. Radiology 197:403-409

29. Vahlensieck M, Overlack A, Müller K-M (2000) Computed tomographic high-attenuation mediastinal lymph nodes after aluminum exposition. Eur Radiol 10:1945-1946

30. Adams TN, Butt YM, Batra K, Glazer CS (2017) Cobalt related interstitial lung disease. Respir Med 129:91-97

31. Davison AG, Haslam PL, Corrin B et al (1983) Interstitial lung disease and asthma in hard-metal workers: bronchoalveolar lavage, ultrastructural, and analytical findings and results of bronchial provocation tests. Thorax 38:119-128

32. Khoor A, Roden AC, Colby TV et al (2016) Giant cell interstitial pneumonia in patients without hard metal exposure: analysis of 3 cases and review of the literature. Hum Pathol 50:176-182

33. Gotway MB, Golden JA, Warnock M et al (2002) Hard metal interstitial lung disease: high-resolution computed tomography appearance. J Thorac Imaging 17:314-318

34. Choi JW, Lee KS, Chung MP, Han J, Chung MJ, Park JS (2005) Giant cell interstitial pneumonia: high-resolution CT and pathologic findings in four adult patients. AJR Am J Roentgenol 184:268-272

35. Dunlop P, Müller NL, Wilson J, Flint J, Churg A (2005) Hard metal lung disease: high resolution CT and histologic correlation of the initial findings and demonstration of interval improvement. J Thorac Imaging 20(4):301-304

36. Mizutani RF, Terra-Filho M, Lima E et al (2016) Hard metal lung disease: a case series. J Bras Pneumol 42(6):447-452

37. Tanaka J, Moriyama H, Terada M et al (2014) An observational study of giant cell interstitial pneumonia and lung fibrosis in hard metal lung disease. BMJ Open 4:e00407. https://doi.org/10.1136/bmjopen-2013-004407

38. Okuno K, Kobayashi K, Kotani Y, Ohnishi H, Ohbayashi C, Nishimura Y (2010) A case of hard metal lung disease resembling a hypersensitivity pneumonia in radiological images. Intern Med 49(12):1185-2118
39. Akira M (2008) Imaging of occupational and environmental lung diseases Clin Chest Med 29:117-131

40. Moreira M, Cardoso A, Silva D (2010) Hard metal pneumoconiosis with spontaneous bilateral pneumothorax. J Bras Pneumol 36:148-151

41. Ruokonen E-L, Linnainmaa M, Seuri M, Juhakoski P, Söderström KO (1996) A fatal case of hard-metal disease. Scand J Work Environ Health 22:62-65

42. Omae K, Nakano M, Tanaka A et al (2011) Indium lung - case reports and epidemiology. Int Arch Occup Environ Health 84(5):471-477

43. Cummings KJ, Nakano M, Omae K et al (2012) Indium lung disease. Chest $141(6): 1512-1521$

44. Amata A, Chonan T, Omae K, Nodera H, Terada J, Tatsumi K (2015) High levels of indium exposure relate to progressive emphysematous changes: a 9-year longitudinal surveillance of indium workers. Thorax 70:1040-1046

45. Nakano M, Tanaka A, Hirata M et al (2016) An advanced case of indium lung disease with progressive emphysema. J Occup Health 58:477-481

46. Eschenbacher WL, Kreiss K, Lougheed MD et al (1999) Nylon flock-associated interstitial lung disease. Am J Respir Crit Care Med 159:2003-2008

47. Kern DG, Crausman RS, Durand KTH, Nayer A, Kuhn III C (1998) Flock workers' lung: chronic interstitial lung disease in the nylon flocking industry. Ann Intern Med 129:261-272

48. Kern DG, Kuhn C, Ely W et al (2000) Flock workers' lung: broadening the spectrum of clinicopathology, narrowing the spectrum of suspected etiologies. Chest 117:251-259

49. Weiland DA, Lynch DA, Jensen SP et al (2003) Thin-section CT findings in flock workers' lung, a work-related interstitial lung disease. Radiology 227:222-231

50. Raghu G, Collard HR, Egan JJ et al (2011) ATS/ERS/JRS/ALAT Committee on Idiopathic Pulmonary Fibrosis. An official ATS/ERS/JRS/ALAT statement: idiopathic pulmonary fibrosis: evidence-based guidelines for diagnosis and management. Am J Respir Crit Care Med 183:788-824

51. Gulati M, Redlich CA (2015) Asbestosis and environmental causes of usual interstitial pneumonia. Curr Opin Pulm Med 21(2):193-200

\section{Publisher's Note}

Springer Nature remains neutral with regard to jurisdictional claims in published maps and institutional affiliations.

\section{Submit your manuscript to a SpringerOpen ${ }^{\circ}$ journal and benefit from:}

- Convenient online submission

- Rigorous peer review

- Open access: articles freely available online

- High visibility within the field

- Retaining the copyright to your article

Submit your next manuscript at $\boldsymbol{\nabla}$ springeropen.com 